\title{
Leukocytes Corrected for Nucleated Erythrocytes Count
}

National Cancer Institute

\section{Source}

National Cancer Institute. Leukocytes Corrected for Nucleated Erythrocytes Count. NCI

Thesaurus. Code C147383.

The determination of the amount of leukocytes, which has been corrected for nucleated erythrocytes, present in a sample. 